\title{
The Interested Expert Problem and the Epistemology of Juries
}

\author{
Alexander Guerrero \\ Rutgers University - New Brunswick, New Jersey, USA \\ Email: alex.guerrero@rutgers.edu
}

(Received 5 July 2021; accepted 5 July 2021; first published online 7 September 2021)

\begin{abstract}
The existence of experts raises a host of interesting questions in social, legal, and political epistemology. This article introduces and discusses interested experts - people who are experts on some topic, but who also have a distinct set of values and preferences regarding that topic, so that they are not well-described as "disinterested" parties. Interested experts raise several distinct problems in social, legal, and political epistemology. Some general questions arise: can we rationally or justifiably form beliefs relying on interested expert testimony? Do they constitute knowledge? Under what circumstances? This article focuses on a specific question in legal epistemology: should interested experts be allowed to serve on juries and, if so, should it be permissible for lawyers to strike them from the pool of potential jurors? My hope is that concentrating on this question will provide insight into the more general questions concerning the epistemology of testimony with respect to interested experts, while also providing concrete recommendations for jury reform to improve the epistemic performance of juries.
\end{abstract}

Keywords: Experts; testimony; juries; interested experts; epistemology of testimony; legal epistemology; peremptory challenge; bias; standpoint epistemology

\section{Introduction}

The existence of experts raises a host of interesting questions in social, legal, and political epistemology. One central set of questions concerns the definition and identification of experts. Who counts as an expert? How can non-experts reliably identify and select experts? How can non-experts judge the relative expertise of two genuine experts? Related to this set of questions are questions concerning who should be selected and included as an expert for purposes of legal and political judgment and decisionmaking. Sitting behind these questions, arguably, are concerns about the epistemology of testimony in cases in which the testifier is an expert and the audience members are not experts. Can we, as non-experts, rationally or justifiably form beliefs relying on expert testimony? Do these beliefs constitute knowledge? Under what circumstances?

In Guerrero (2017), I addressed the question of the epistemology of testimony in cases in which non-experts are interacting with experts whose incentives might be imperfectly aligned with one's own. In this paper, I introduce and discuss what I call interested experts - people who are experts on some topic, but who also have a distinct 
set of values and preferences regarding that topic, so that they are not well-described as "disinterested" parties.

Interested experts raise several distinct problems in social, legal, and political epistemology. Some of the same general questions arise: can we rationally or justifiably form beliefs relying on interested expert testimony? Do they constitute knowledge? Under what circumstances? In this paper, I will focus on a few very specific questions in legal epistemology: should interested experts be allowed to serve on juries and, if so, should it be permissible for lawyers to strike them from the pool of potential jurors? My hope is that concentrating on these more specific questions will provide some insight into the more general questions concerning the epistemology of testimony with respect to interested experts. Before getting to these questions, however, it is necessary to first say something more about the foundations of legal epistemology, and to introduce and refine the idea of an interested expert.

\section{Foundations of legal epistemology}

In many cases of policymaking and all cases of rendering legal judgments against specific individuals or entities, those actions will be correct or good (or both) only if certain other facts obtain. Convicting a person of a crime is morally good only if the person committed the crime. An administrative official or administrative law judge signing off on a specific threshold, T, for lead and water safety is a good option only if it is in fact safe to drink water if it contains lead levels below T. (Notice that these are only necessary conditions.)

For any action, there are what we might call factual conditions of success: those facts that must obtain for that action to be either a moral or prudential success. These facts can either be necessary preconditions for success, or something closer to being constitutive of success. Legal and political actions, like other actions, can be more or less successful along both moral and prudential dimensions - and their success is partly a function of whether the relevant factual conditions obtain. A prosecution of a defendant resulting in a conviction will only be morally successful if the person convicted committed the crime in question. An act of legislation designed and enacted to address some problem is only successful if the problem is real and the problem is actually addressed by the legislation.

For a subset of legal and political actions - actions that might be described as the State acting against particular individuals - these actions are permissible only if certain triggering conditions obtain. ${ }^{1}$ These actions include things like the State imprisoning or

\footnotetext{
${ }^{1}$ There might be other kinds of normative constraints on action - such as acting only on those propositions that one knows or (at least) that one is justified in believing, or treating a proposition as a reason for action only if one knows that proposition. For relevant discussion, see e.g., Fantl and McGrath (2002, 2009, 2012), Lackey (2007), Hawthorne and Stanley (2008).

We might expect for there to be institutional analogues of these so-called "knowledge norms." These are norms of the form: $\varphi$ only if one knows some specified proposition, $p$ (where $\varphi$ might be 'assert that $p$ ', 'believe that $p$ ', 'treat $p$ as a reason for action'). Consider, for example, the following norm:

If an institution, $I N$, can only permissibly $\varphi$ if it is the case that $p$, then $I N$ can only permissibly $\varphi$ if $I N$ knows that $p$.

There then would be questions of how to conceptualize what it is for an institution to know (or believe, or treat as a reason). These analogues might either focus on institutional or collective knowledge, action, assertion, belief, and so on. Or they might identify relevant individual institutional actors or sets of actors for whom these knowledge norms apply (either as an instance of the general case, or not).
} 
punishing individuals for violating the criminal law, removing children from the custody of one or more of their parents, involuntarily committing people to mental health or other medical institutions, deporting individuals for violations of immigration law, and so on. There are circumstances in which these actions can morally permissibly be taken, but only under very precise moral conditions. Individuals have preinstitutional moral rights against State interference, so that this kind of State action against us is morally impermissible except in those cases in which these moral conditions obtain. In a decently good legal/political system - a system that we might call even minimally legitimate - there will be legally codified 'triggering' conditions that allow State action only in those cases in which the relevant moral conditions obtain.

Let us focus, then, on the context in which the State will or might take action vis-à-vis a particular individual, $\mathrm{P}$, by maintaining that, because certain legally codified triggering conditions obtain in P's specific situation, that law should be applied to $\mathrm{P}$, and certain consequences may, or should, follow with respect to $\mathrm{P}$. This describes, albeit abstractly, many of the direct confrontations that occur between the State and particular individuals. To identify some of the main categories of cases, it includes all situations in which (a) individuals are said to have violated the criminal law, (b) immigration law is applied to particular individuals to remove them or to alter their immigration status, (c) an individual is deemed to be mentally ill and in need of involuntary commitment to a medical facility or involuntarily administered medication in order to prevent him from harming himself or others, (d) it is suggested that some individual does not qualify for a government benefit that he has been receiving or has attempted to receive, (e) the State threatens to remove a child from a parent's custody and to terminate that parent's parental rights, and, arguably, (f) the State maintains that some individual or corporation (owned, collectively, by some group of individuals) violated an administrative regulation (e.g., by exceeding the allowable limits of expelling some pollutant into the environment). In these cases, the State can permissibly act only if the relevant underlying moral conditions obtain. ${ }^{2}$

Acknowledging the ways in which we - and the institutions we might create - are neither omniscient nor infallible, some error is tolerated from both a moral and a legal perspective. Error arrives from two directions. The first is that the legally codified conditions might not match the actual moral conditions. Perhaps the standard for when children can be removed from their parents is written in a way that presumes a certain kind of family structure, so that even some morally unobjectionable departures from that structure are - inappropriately - treated as grounds for removing children and putting them into State custody. For the purposes of this paper, I will set aside errors of this kind, assuming that the legally codified triggering conditions match the actual moral conditions tolerably well.

A second source of error comes not in the content of the legally codified triggering conditions, but in the application of those legal rules to particular cases. For any particular case, there is a question of whether the underlying facts are such that the legally codified conditions are actually satisfied. We are not omniscient, nor are our

Even in the individual case, there is a question of what kinds of norms these are - are they norms of practical rationality, moral norms, epistemic norms, norms of communication? Or some combination of these, depending on the details of the case? Or are they constitutive norms of various actions or practices, so that one counts as engaging in that action or practice just in case one abides by this norm? For the purposes of this paper, I will assume that whatever kinds of norms these are, they either require just as much as the legal or political or moral norms that will be my focus, or they do not compete with, trump, or otherwise override those norms.

${ }^{2}$ For more extended relevant discussion of the State versus Individual context, see Guerrero (2012). 
institutions. We will sometimes make mistakes. But there is a morally grounded requirement to avoid these mistakes. Accordingly, extensive legal and institutional processes must be present to determine whether these "triggering conditions" obtain in a particular case. Individuals have moral rights to the existence of these processes - rights that have been enshrined in law in minimally legitimate political systems, often under the heading of "procedural due process" rights.

In at least these State versus Individual contexts, legal rights to procedural due process (grounded in moral rights against inappropriate State infringement on individual freedom and autonomy) are rights to excellent, high epistemic quality institutional processes to ascertain whether the legally codified triggering conditions really do obtain. Under most real-world political conditions, there will be practical constraints on how much time, money, and other resources can be spent attempting to ascertain the underlying facts.

There may also be moral constraints on these investigative processes, constraints that may work against the epistemic quality of those processes. Consider, for example, the rules governing how evidence can be obtained that stem from autonomy and privacybased considerations. In the United States, these include Fourth Amendment rights against unreasonable searches and seizures and rights against untargeted, general warrants. To ensure that these rules are adhered to, there may be prohibitions on using epistemically valuable evidence that has been obtained in violation of these rules. ${ }^{3}$ There are hard questions about how to balance the moral interests in, say, privacy, against the morally grounded interest in high epistemic quality process in those cases in which these interests come into conflict. I will discuss some of these conflicts below, but for most of the discussion in this paper I will focus on cases that do not involve this kind of conflict.

If there is a morally grounded right to high quality epistemic process in these State versus individual cases, we should ask: what makes an institutional process of high epistemic quality? It is plausible that institutional epistemic virtues and aims will be similar to individual epistemic virtues and aims: to produce and acquire knowledge through processes of discovery and investigation; in particular, to produce and acquire knowledge of those propositions that are relevant and important to the potential State action and to whether the relevant triggering conditions are actually satisfied in a particular case; to have true beliefs about the facts of particular cases; to avoid error and false belief; to have one's (whether an individual or an institutional agent) beliefs and confidence levels be appropriately responsive to one's evidence. There may be other aims and virtues that might also be on this list, whether fundamentally or only derivatively: to be able to identify reliable sources of evidence and testimony; to employ beliefforming processes that are rational, justified, reliable, safe; to be able to engage with and draw from diverse sources of knowledge and evidence, including extant technical, esoteric, and expert knowledge; to accurately and appropriately assess, weigh, and evaluate evidence; and to organize and disseminate evidence and knowledge so that it is readily available and appropriately salient for decision-making purposes.

On one view, we should understand institutional (social, political, legal) epistemology as veritistic, focused on the production and promulgation of important and relevant true beliefs, and the avoidance of error (false belief) and ignorance (the absence of true

\footnotetext{
${ }^{3}$ And there may be some rules that are justified in part on moral grounds, in part on epistemic ones, such as rules allowing people to refuse to testify in their own case. We might have a moral right against testifying against ourselves. And allowing the State to compel people to testify in their own case might also be a route to epistemic error, because of worries about forced (but false) confessions, the potential for manipulating how individual testimony is provided, and so on.
} 
belief). Of legal institutions, we can ask, then, in a Goldmanian vein: which legal institutions and practices "have a comparatively favorable impact on knowledge [understood in the weak sense of true belief] as contrasted with error and ignorance" ? ${ }^{4}$ On this kind of view, other epistemic values such as justification and warrant and perhaps even understanding are either of no or only secondary importance when thinking about political and legal epistemology. We care about how truth-conducive our practices and institutions are; we don't otherwise or independently care about whether they are justification-conducive, etc.

I won't argue for this view here, but I incline toward thinking that the primary focus of institutional epistemology should be on evaluating the extent to which institutions produce, identify, and rely upon true beliefs that are relevant in the particular institutional context, rather than on whether they exhibit these other epistemic values. Part of the reason for this is that it is unclear whether institutions are the kinds of things that can properly instantiate these other kinds of epistemic value. But that is a topic for another day.

Whether we go in for a veritistic view or not, we should not only be concerned with the role that practices and institutions can play in maximizing, promoting, or spreading true belief and minimizing ignorance and false belief within a community or institution. And that is true even if we concentrate our attention on important or relevant (somehow defined) beliefs within the relevant social or political community or institution. That might be one veritistic dimension along which we can engage in epistemic evaluation of practices and institutions. But it is not the only one.

That is so because there is more than one way in which practices and institutions can be truth-conducive. One way is to increase the number or percentage of true beliefs relative to false beliefs, or of significant truths accepted compared with significant errors made - but to do this by improving the epistemic situation of particular individuals in the community or institution in terms of what they believe. Call this institutional epistemic evaluation with respect to veritistic effects on individuals: to what extent does the institution promote true belief and the avoidance of false belief of those individuals who are affected by the institution?

But institutions and practices can also affect whose beliefs - whether true or false matter, and how much they matter, and this can lead institutions to have something like collective or "effective" epistemic virtues, even if they don't affect whether particular individuals in the community have any more or fewer true or false beliefs. For example, institutions can help minimize the significance of false belief by preventing those beliefs from influencing the decisions that are made and the actions that are taken, or by significantly reducing the weight of such beliefs. Or they might exacerbate the significance of false belief by giving the most power to those with systematic false belief or entrenched ignorance. There are plausible individual-level analogues of these kinds of mechanisms, whereby we might try to avoid being influenced by biases (with perhaps uneven results), or try to rely on what we take to be our epistemically best beliefs and sources of evidence. But whether present in the individual case or not, these are a central feature of political and legal institutions. Call this institutional epistemic evaluation with respect to veritistic structural quality: to what extent does the institutional structure ensure that the effective or factual predicate beliefs of the institution (including the beliefs of the relevant, empowered institutional actors) are true? In particular, we might ask: to what extent does the institutional structure ensure that the effective institutional beliefs about the underlying factual triggering conditions of particular cases are true?

\footnotetext{
${ }^{4}$ Goldman (1999: 5).
} 
With this background in place, we can see many particular aspects of a legal system as designed to improve the legal system's veritistic structural quality. There are various institutions and individuals occupying official roles who investigate the underlying facts and have to then present those facts to additional individuals: police officers and police detectives, immigration officers, child protective services, administrative officials, prosecutors, State lawyers, individual defense lawyers, grand jurors, petit jurors, judges. There are selection procedures that determine who can serve in these roles, what credentials and training they must have, and when they can be properly excluded or removed from serving in the role. There are the specific codes of conduct that regulate how individuals in those roles may permissibly behave, with much of the content of those codes of conduct borne of epistemic considerations. There are the rules of investigative and court procedure concerning the discovery, introduction, and handling of non-testimonial evidence; the soliciting, recording, presentation, cross-examination, and use of testimony; and the selection, qualification, and use of experts and expert testimony in particular. There are rules regarding how various kinds of evidence can be used, for what purposes, and with what kind of probative value. There are rules regarding which parties in the case have the burden of proof. There are the detailed, precisely specified triggering conditions (as discussed above) or "elements" of the offense that set out what, precisely, must be proved. There are standards of proof ("beyond a reasonable doubt," "preponderance of the evidence," etc.) that set out the required level of confidence that those rendering verdicts must have in their judgments or (depending on one's interpretation of these standards) an approximation of the statistical likelihood that the relevant triggering conditions are satisfied.

Although not usually discussed in epistemological terms by people with philosophical training, these rules, procedures, and roles are grounded in epistemological considerations. As noted above, there are also non-epistemic considerations that enter in to affect the precise contours of these rules, procedures, and roles. And we can understand longstanding debates about the merits of, say, adversarial versus inquisitorial systems of adjudication as debates about how those different systems fare in terms of veritistic structural quality.

In what follows, I will focus on one category of person, what I call the interested expert, and raise questions about the veritistic case for including or excluding such a person in various roles within the legal system. In particular, I will focus on the interested expert and the role of jurors, the current rules governing who can be excluded from serving as a juror, and on what grounds. My focus on this topic is motivated by the view that this is one of the most central things that the current procedural system gets wrong on an epistemological level.

\section{The interested expert}

There are some groups of people, G, such that the following is true:

(1) epistemic excellence: members of $\mathrm{G}$ are highly epistemically valuable with respect to some set of questions, $\mathrm{Q}^{*}$,

(2) distinctive interests: members of $\mathrm{G}$ are likely to have some socially distinctive set of preferences, interests, or values, $\mathrm{V}^{\star}$, relative to the broader political community, and

(3) reasonable divergence: the distinctive set of preferences, interests, or values, $\mathrm{V}^{\star}$ is neither morally nor rationally required for non-G individuals - or it is at least controversial whether it is morally or rationally required for non-G individuals.

It is a contingent fact that there are groups like this, and it is a contingent fact how large they are, how many such groups there are, and so on. It need not be that members of G 
have entirely distinct interests, preferences, and values. Indeed, these might be fairly specific values or preferences over one topic. Additionally, the reasonable divergence condition is meant just to flag that the members of $\mathrm{G}$ are not necessarily both distinctive and correct in preferring or valuing as they do with respect to $\mathrm{V}^{*}$.

Although more could be said about what it is for a person to be epistemically valuable with respect to a question, $\mathrm{Q}$, we can work with a notion on which such a person is able and likely (a) to answer Q correctly, or with considerably greater accuracy than other people; (b) to identify the considerations that are relevant to answering Q; and/or (c) to deploy methods in the future that will help develop answers to or understanding $\mathrm{Q}$ or other similar questions.

Once identified in this way, many groups clearly fit these parameters. It is possible that all of us are members of such groups, if we expand the Qs under consideration beyond just those that are of likely relevance to law and politics. Here are some examples of members of different groups that appear to satisfy the above conditions:

Ginny Morgan: works as a biochemist and human safety specialist for a company that is focused on developing safe and responsible GMOs. After working at the company for some time, she started to become politically active in pushing for international regulations that permit use of responsibly developed GMOs, as she believes they are vital to reducing world hunger, and thinks that GMOs have been unfairly maligned.

Sarah Brady: after an assassination attempt paralyzes her husband, she spends much of her adult life learning about guns, gun safety, and different gun control policy options. She is a staunch advocate of robust gun control and has spent much of her adult life lobbying for more restrictive gun laws.

Joseph Hunter: raised in a rural libertarian household that focused on teaching children about guns and other weapons, both for hunting and for responsible selfdefense. He is a very knowledgeable, highly skilled, and responsible gun owner, and helps to run clinics teaching others about guns and gun safety. He is a staunch opponent of gun control for most of the country, and advocates instead for extensive gun education and training.

Jane Doe: a woman in her mid-30s who has been sexually assaulted and sexually harassed on multiple occasions, and been through years of therapy and participated in several group sessions engaging with others who had been through similar experiences. She now works as an advocate for women who have been sexually assaulted, working on reforming the legal system and other adjudicatory systems so that they better respect the rights and interests of those who have been assaulted and harassed.

Langston Smith: a 50-year old man who grew up in North Philadelphia, in what is derisively called the "Philadelphia Badlands," an area with a diverse mix of ethnicities, including significant numbers of Puerto Ricans, African-Americans, Irish-Americans, and Dominican-Americans. There is a high concentration of organized street gangs, open-air drug dealing, heavy users of drugs, and high levels of other associated crime. Smith himself was involved in both gangs and drugs, and spent 12 years incarcerated as a result of this involvement. He obtained a college degree while in prison and a MSW degree after being released from prison, focusing on addiction and substance abuse, and now works as an advocate for 
impoverished communities in Philadelphia, for prison reform, and for improvements in drug and substance abuse treatment.

Doctor Brantley: a 69-year-old pulmonologist (a doctor who specializes in treating diseases of the lungs, such as lung cancer and chronic obstructive pulmonary disease) who has spent much of her career treating lung cancer patients and researching causes of and therapies for lung cancer. Beginning in the middle of her career, in the early 1990s, she started to become an advocate of more stringent regulation of cigarettes and the manufacture and marketing of cigarettes.

Colonel Marshall: a 64-year-old retired colonel and current engineer who spent 30 years in the military, was a West Point graduate, and now advises Northrop Grumman as they develop new military systems technology. He is an advocate of expanding U.S. military presence throughout the world as a way of reducing "hot" war and is an advocate for an increasing use of drones and other unmanned military equipment for actual military engagement.

Bea Jackson: a 45-year-old woman with a life-long love of bees. She is an insurance salesperson, but as a side interest she has learned about all different kinds of bees, traveled the world to see different kinds in remote places, raised many kinds of bees as an amateur beekeeper, and watches documentaries and reads books about them. In the course of doing this, she learned about the way in which climate change, industrial monoculture agriculture, and widespread use of certain pesticides is affecting bee populations in North America and around the world, and has become an advocate for protecting the environment, ending ecologically unfriendly industrial agriculture, and combating the use of certain pesticides.

In all these cases, the individuals in question have some distinctive set of knowledge borne of experience, education, training, or some combination of these - but also have strong and distinctive interests and values.

The claim is not that they are wildly divergent from the broader community in terms of their interests or values - indeed, many people may share them, perhaps while lacking the distinctive knowledge, perhaps while possessing it. The difficulty is that we can imagine contexts in which - if one of these individuals were chosen as a juror, expert testifier, or political decisionmaker - some would feel that the individuals would be biased.

Although we might acknowledge they possess some relevant expertise, or something like expertise, they are not disinterested experts. To the contrary, they are interested experts. The problem comes in how or whether to include them in the decisionmaking process of legal and political institutions.

It is worth stressing that this is fundamentally an epistemic problem. The case for inclusion is that they have expertise, which should be epistemically valuable on veritistic grounds. These individuals are more likely than most to have true beliefs with respect to their $\mathrm{Q}^{*}$ questions, and so we might expect in many cases that including their input will result in a more truth-conducive process. The case for exclusion is that they are not disinterested, they might even be well-described as "biased" - which is generally epistemically troublesome, again on veritistic grounds. Their interests might affect how they filter evidence in particular cases, what their priors are with respect to relevant factual information, and how or whether they provide fully truthful testimony. Let us call this the Interested Expert Problem. 
This problem is heightened in those cases in which all or almost all people with the relevant expertise will be distinctively interested in this way. The problem is most acute when all the people with the relevant expertise are both interested, and in which those interests all point in the same direction.

Let me clarify the Interested Expert Problem in a few ways. First, we should distinguish between different senses in which a person might be interested. People are complicated, and their motivations can be complicated. The fully accurate picture could be quite complicated, but let us distinguish between two rough categories of interests:

Narrow interests: those states of affairs that an individual, A, prefers because A believes they will lead to or constitute improvements in A's personal wealth, health, or the wealth or health of A's close friends and family.

Broad interests: those states of affairs that an individual, A, prefers because A believes those states of affairs to be morally, prudentially, or otherwise better for people or entities other than just A herself or A's close friends and family - this might be for one's community, this population of non-human animals, one's nation, all existing people, all existing and future people, all sentient creatures, and so on.

There might be states of affairs that one prefers both because of narrow interests and broad interests. We can call these cases of "mixed" interests.

As noted, people are complicated, and it can be difficult to disentangle the different beliefs, desires, and reasons that drive them to do what they do. That said, it is plausible that in the cases described above, the Interested Expert is interested, but not just in a narrow way. They are not just looking out for their own pocketbooks, or to advance the interests of their own families. There are worries about being selfdeceived about this kind of thing - adopting one's broad interests for what one takes to be other-regarding reasons, but which in fact are rooted in one's realization of where one's narrow interests lie. But I think many of these cases will not be like that. For the purposes of this discussion, let us focus on Interested Experts whose interests are not just narrow. They will provide us with plenty of trouble in their own right.

Another important clarification is related to the previous one: there are different explanations, different causal histories, of how people come to be Interested Experts. Again, people are complicated, but as three rough types, consider the following:

Common cause: Having certain experiences is a common cause of the epistemic excellence with respect to $\mathrm{Q}^{*}$ and of the distinctive interests with respect to $\mathrm{V}^{*}$.

Joseph Hunter, who grew up in a gun and hunting household and now promotes responsible gun ownership.

Jane Doe: who experienced sexual assault and recovery from that assault, and now works as an advocate on the issue after seeing how poorly it is often handled.

Langston Smith: who grew up in the "Philadelphia Badlands", was a drug user, involved with gangs and sale of drugs, and was incarcerated, before turning to academic study of drugs, addiction, and incarceration, and now works as an advocate on these issues. 
Interests cause expertise: having distinctive interests $\mathrm{V}^{\star}$ causes one to seek out more evidence and information about topic $\mathrm{Q}^{*}$.

Sarah Brady: whose life was changed dramatically as a result of gun violence, leading her to care about the issue, learn about it, and become a zealous advocate.

Bea Jackson: who happens to love bees, leading her to learn all about them, leading her to learn about the dangers confronting them.

Expertise causes interests: developing the epistemic excellence with respect to $\mathrm{Q}^{*}$ leads one to have distinctive interests $\mathrm{V}^{\star}$.

Ginny Morgan: who works on GMOs, knows all about them, and comes to see them as an important option that is being unfairly and ignorantly ignored, and so works as an advocate to overcome those political obstacles.

Doctor Brantley: the pulmonologist who becomes an anti-smoking advocate after years of seeing lung cancer patients.

Colonel Marshall: whose military training, experience as an engineer, and education have led him to have certain views about how to promote peace and conduct war when doing so is necessary.

Again, details and subtleties might matter for how we classify particular cases. Does Langston Smith's expertise really end up coming more from his life experiences growing up in North Philadelphia, or from his MSW degree? Does Colonel Marshall have the interests he does because of his education and work experience, or did he seek out that education and work experience because of antecedent beliefs, interests, and values regarding the role of the U.S. in the world? Still, despite those complications, it is useful - for epistemic and political reasons that will be discussed in a moment to consider these different causal stories a bit more.

\section{Types of interested experts}

\subsection{Common cause}

Our experiences shape us along at least two dimensions: (1) they affect what we believe and know and (2) they affect what we care about. In other terms: they affect what we become experts about and they affect what interests we have.

The common cause cases of interested experts involve people who had life experiences that were formative both in affecting what they know and in affecting their values, what they care about. Of course, all experiences have the potential to affect us in these different ways. The difference here is one of degree, not kind. In these common cause cases, the effects are deep, sustained, profound, and possibly hard to disentangle. What came first, the change in knowledge, or the changes in concern and affection? This can be hard to answer in actual cases, and it is plausible that there are complicated and extended interaction effects that end with interested experts of a certain kind.

Drawing on the work of Hartsock (1987), Hill Collins (1990), Harding (1993), Mills (2007), Medina (2013), and others, we might invoke various forms of standpoint theory to note that what one is able to notice and explain may be partly a function of one's social position and attendant social experiences. This might create a distinctive kind of expertise in those who have had these background experiences. And those 
experiences might also give rise to a distinct set of values, preferences, and concerns. For example, those who are oppressed often have to learn in much greater detail about their oppressors than the reverse. As Baldwin (1993 [1961]) puts it, "I have spent most of my life, after all, watching white people and outwitting them, so that I might survive." Anzaldúa (1987) sounds a similar theme in referring to what she calls "la facultad" the capacity to notice things others might not, and to see deeper structure below surface phenomena. On her view, this capacity, which might constitute a kind of expertise with respect to some questions, develops in those who do not feel psychologically or physically safe, particularly those who are socially marginalized and subject to harm: "when we're up against the wall, when we have all sorts of oppressions coming at us, we are forced to develop this faculty so that we'll know when the next person is going to slap us or lock us away" (Anzaldúa 1987: 60-61).

It is worth stressing that the distinctive knowledge or expertise possessed on this kind of account needn't be exhaustive social scientific knowledge regarding the full complex structural causes of oppression and social inequality. The relevant knowledge may be much more microscale, situational, social, and emotional, concerning how people do or are likely to behave under various circumstances, how certain actions and events make people feel, what subtle and perhaps largely unnoticed obstacles might exist to limit the effectiveness of a rule or policy, and so on.

Furthermore, the better epistemic position of the relatively oppressed and marginalized - on some questions - might be merely comparative. Mills (2007), for example, draws on the example of the protagonist in Ralph Ellison's Invisible Man to illustrate how whiteness in America can be associated with systematic misperception, due to cultivated "white ignorance" about all manner of things, including historical facts about race and discrimination and injustice and oppression. As Ellison's protagonist comments, this misperception is not due to any physical problems, but rather to "the construction of their inner eyes, those eyes with which they look through their physical eyes upon reality." This ignorance is created through miseducation, intentional historical non-remembering and non-memorializing, intentional misinformation, and through the use of stereotyping, stigma, and vilification. Harding, Hartsock, and others also make similar points with respect to understanding of gender, sex, society, and sex- and gender-based oppression.

The focus on standpoint theory has been on how experience, particularly experience occupying different social positions, can affect what one knows. The least controversial way in which one might make the case for this view is just by noting how differently situated people will come to encounter different evidence over the course of their day, over their weeks, months, and years of living in the world. Standpoint theorists mostly don't use the language of expertise, but it is plausible to call this a distinctive kind of expertise one might come to have, borne of particular life experience. On the view suggested here, this can result in expertise with respect to a particular set of questions, but it can also result in a difference in what one cares about, prefers, and values.

Note that these needn't be fundamental or foundational value differences. It might be that those are very similar across different groups. But it might result in differences in, say, whether a person like Jane Doe favors a preponderance of the evidence standard in sexual assault cases on college campuses, because she knows how bad sexual assault can be, how significant a harm it is, how unlikely false accusations are, how rare and difficult reporting is, how hard it is to have conclusive evidence, and so on - and so has views about how we ought to balance the various risks of errors.

Their expertise and their distinctive interests over some topics both derive from their lived experiences, from the particular standpoint they have occupied in the world over a significant period of time. 


\subsection{Interests cause expertise}

In some cases, our interests - what we care about, what we value, what matters to us might drive us to learn a lot about some particular corner of the world. Familiar examples of this abound. Think of gourmands, connoisseurs, the audiophile who is obsessed with building the perfect set of speakers, the civil war history buff, the person who is interested in his ancestry and becomes skilled at sifting through genealogical databases.

For some of the interested experts in this category, it might be opaque exactly where the initial interest and concern about the topic comes from. Why does Bea Jackson love bees? Maybe some early childhood experience? Who knows?

In other cases, they will be quite transparent: if you have young kids, you start caring a lot about what the local schools are like, and learning all about the existing schools, planned changes, alternatives, and so on. In the case of someone like Sarah Brady, it was loving her husband and seeing the devastating result of gun violence on his and her life.

Some of these interests will have legal and political implications, driving people to push for various kinds of legal and political reform. Others will just lead them to eat and drink too much, or to spend too much on high-end audio equipment. Some of these interests will be silly and insubstantial, but others may be quite morally serious. Think of the person who really loves animals, and fights for environmental protections and an end to factory farming.

Their love or concern for someone or something leads them to seek out knowledge and learn much more about that topic than they would have otherwise, and more than most people do. Note that the focus here is on people who are interested experts on a topic, meaning that they do have a distinctive set of values and preferences relating to the topic. So, I am not including in this category all of those people who have an interest in getting a job, and so spend time getting an education or learning a trade so as to be employable in a particular field. These people might end up having expertise, but they will not necessarily be interested experts in the sense relevant here.

\subsection{Expertise causes interests}

Finally, consider those cases of interested experts in which the person first develops the expertise, and this subsequently shapes the person's values or interests - at least with respect to some practical domain. Common cases here are those like Doctor Brantley or Ginny Morgan - people who start in some line of work, or in some course of study, develop expertise, and come to start caring about what it is that is causing the problems about which they now have expertise. They weren't interested in this way at first, or not transparently, but they are now.

I worked for several years in Boston teaching in prison at the Suffolk County House of Correction. There was a woman teaching in the education department there who had sort of fallen into the work - she was far from anything like a true believer when she started the job. Still, as she had seen many men really take to learning, become literate, work toward their GED, earn college credit, and then succeed on the outside, she had come to be a big believer in the value of educational opportunities and vocational training in prisons. She didn't become politically active, but there is no doubt it affected how she would vote and think about prison reform. Of course, she also came to have personal knowledge of and attachments to her students, which no doubt shaped her views. But it is also plausible to say that the core thing that happened was that she learned what prison education really could do.

As these examples suggest, the acquired expertise might be through work experience, or through formal education, or through something less structured than either of those. The common thread is that somehow learning about this area in detail affected what 
one cared about and how one was disposed to act. For these people, learning came first, the broader interests and personal concern came later.

So, a quick recap. There are people in our communities who are plausibly well described as interested experts, at least with respect to some questions. Perhaps all of us could fit this description for the right set of questions. These "interested experts" can differ in the way in which they came to be both interested and experts. There are what we might call "Livers": people whose lived experience serves as a common cause of both their expertise and their distinctive interests with respect to the issue in question. There are "Lovers": people who started with a love or distinctive interest in some topic, and this led them to become experts with respect to that topic. And there are "Learners": people who started by learning a lot about a topic, and came to have interests and concerns as a result of what they learned.

Before proceeding, let me consider a worry that might apply most centrally to interested experts who fall into the first two categories: Livers and especially Lovers. The worry goes something like this. Because their interests, concerns, and affections either pre-date or are intermingled with the development of their supposed epistemic excellence with respect to the set of questions, $\mathrm{Q}^{*}$, there is a worry that they will have only selectively engaged with relevant evidence, so that they are not really experts at all with respect to $\mathrm{Q}^{*}$. Instead, they may know quite a bit about one side of the issue, but not about the full complexity of the issue. This worry would seem to deny the possibility of interested experts, or to suggest that the category of interested experts is smaller than I have suggested. This suggestion would deny that there are people who are genuine experts on these topics of interest, but who also had these interests and affections either before or at the same time during which they developed their expertise. The suggestion might be that this kind of antecedent or concurrent interest or affection effectively blocks or makes impossible the development of genuine expertise.

One can hear echoes of this kind of worry from Heath (2015) and others who bemoan what they call "me studies" - people studying subjects that are intimately bound up with their own experience and in some cases, oppression (for example, African-Americans studying and writing about racial injustice in the United States). For Heath, the central mechanism isn't selective engagement with evidence, but the concern that some evidence and counterarguments wouldn't be offered to people in certain groups, for fear of insulting or offending them. But a more general suggestion is that having significant interests actually does make it impossible to develop expertise on a topic. There are only disinterested experts, this suggestion maintains. All others are at best only pseudo-experts.

Put this way, it is not a plausible worry. First, it is not clear why having interests or affections of a certain kind will necessarily impede expertise. Heath, for example, is quite clear that we could have discursive norms that would overcome some of the concerns about what evidence is provided to whom. Individuals could develop skills of selfcriticism, strategies of engagement with disinterested or differently interested others, and other means of counteracting potential biases or lacunae in their own perspective.

Second, there might be some topics for which everyone who is a plausible candidate expert will be interested in various ways. Think of members of a profession such as medicine or law. When the question comes about how to regulate those professions, the most likely experts are people who will be people who also have at least some significant intertwined interests. It would be a strong result to suggest that no one was an expert in these cases, just because everyone had some interest. 
Or think of topics like "What is it like to grow up in the Philadelphia Badlands?" Of course, one might take a sociological approach and interview lots of people who have had those experiences, and try to draw some conclusions. But, first, that will be to rely on these people as certain kinds of authorities, despite their likely interests. And, second, there might be some cases in which proceeding in this way leads one to miss out on crucial dimensions of the question, to import one's own expectations and prejudices (a common problem throughout the history of anthropology and sociology) as a 'disinterested' outsider, and to reach inapt answers and to offer faulty interpretations as a result.

More might be said, certainly, but I think it is important to cast a critical eye on sweeping suggestions about the effects that concerns, interests, and affections might have on individual expertise.

These three categories are not meant to have sharp or clear boundaries. Still, they offer something of a rough typology. The next question, which returns us to concerns of legal epistemology: what do we do with Interested Experts? In particular, do we include them in our legal and political decisionmaking? Does it matter if they are Livers, Lovers, or Learners? Do they count as objectionably biased? Does our view differ depending on the specific role: jury member, political decisionmaker, judge, testifier in court, prosecutor, administrative agency bureaucrat, and so on?

There are a number of possibilities for each context. We could require that such people are excluded, we could permit them to be excluded, we could require that they be included, we could intentionally aim to include more of them than proportionally expected, or we could decide randomly who will or won't be included - meaning that they would be included roughly proportionate to their number in the general population. In the rest of the paper, I will consider the problem of interested experts thinking specifically about juries and potential jurors.

\section{The epistemology of juries}

In systems that use citizen juries, like in the United States, the randomly chosen nature of the jury is often hailed as a central democratic component of the system, reflecting a deep commitment to the fundamental equality of every citizen in the community. Although admitting of this kind of purely democratic justification, sounding in basic conceptions of political morality - self-government, liberty, autonomy, political equality, and the like - I think the deeper foundation of the citizen jury is epistemic.

Recall that there were two significant worries about ways in which the State could act erroneously with respect to particular individuals. One source of error came from the content of the law, so that the legally codified triggering conditions would allow State action against individuals in cases in which that action was not actually morally permissible or morally appropriate. The second source of error came in the potential misapplication of fine law against particular individuals, because the underlying factual conditions of the case didn't actually satisfy the legally codified triggering conditions.

Juries help prevent both kinds of error. One way in which they can address the first kind of error is through jury nullification. The jurors might come to believe that the legally codified triggering conditions are satisfied, but that the underlying moral conditions are not satisfied in this particular case, and so might find for the individual despite what the law would require. These cases are somewhat less common and are certainly more controversial, with debates arising about whether this is a proper function of the jury. ${ }^{5}$

\footnotetext{
${ }^{5}$ For relevant discussion, see Brooks (2009), Huemer (2018).
} 
Juries more centrally protect against the second kind of error, preventing the State from acting against individuals in cases in which the legally codified triggering conditions are not actually satisfied in a particular instance.

One way in which they do this is simply having randomly chosen citizens standing in as protection against the intentional misuse of State power against particular individuals. The State cannot simply allege that a particular individual is in violation of the law; there is a process to determine whether that is actually the case, and randomly chosen citizens will end up being the arbiters of whether the facts on the ground satisfy the legally codified triggering conditions for State action. This is part of the democratic function of juries, of course, but it should also be counted toward the veritistic structural quality of systems that employ juries, as it helps avoid error of this kind.

A second way in which citizen juries contribute to veritistic structural quality is through the expertise of the citizens regarding what is normal, reasonable, morally permissible, unobjectionable conduct in ordinary life - and what is not. Law frequently invokes what might be called folk normative standards regarding individual conduct as a way of determining when conduct was reasonable or appropriate or normal, and when it constitutes recklessness or negligence or social deviance. Given the complex specificity of facts in legal cases, it would be hard (costly, laborious) or even impossible to have social scientists or other kinds of experts tell us exactly what the 'folk' or 'community' normative standards would require in particular cases in a way that would be satisfactory by the lights of their normal empirical methods. Citizen, lay juries can be an epistemic shortcut around this concern. This can be helpful both for ascertaining whether the legally codified triggering conditions obtain, and for assessment of whether the underlying moral conditions obtain (in the event that nullification might be appropriate).

Third, there are potential epistemic benefits to having randomly chosen, and thus demographically representative, citizens serving on juries. ${ }^{6}$ As noted above in the discussion of the way in which experience might confer expertise, different kinds of experiences might lead one to think about the world in different ways or to have encountered different bodies of evidence - all of which might be epistemically useful in determining whether the facts in a given case satisfy the legally codified triggering conditions. If there is diversity of experience within the community, having a random sample of people might well inject useful epistemic and cognitive diversity into the decision-making body. Here, we might bring in standpoint theory, or echo points made by Aristotle in his famous feast analogy, and, more recently, Landemore (2013) and Page, regarding the epistemic benefits of diversity along various dimensions. Page (2007) and others have offered formal work suggesting that cognitive diversity is epistemically advantageous. Aristotle, Landemore, and others suggest that diversity in terms of life experience including occupational experience, religious experience, cultural experience, experience occupying different social positions, educational experience - is important for epistemic reasons. The basic point seems undeniable. Because individuals are chosen at random from the jurisdiction, they are likely to be an ideologically, demographically, and socioeconomically representative sample of the people in the jurisdiction - certainly more so than they would be if juries were eliminated in favor of bureaucratic or technocratic officials. Assuming true random sampling and a long enough run, we should expect a descriptively proportional number of people in the room really will have firsthand knowledge of being an engineer, police officer, primary caretaker of children, nurse, construction worker, waitress, cashier, plumber, social worker, truck driver, scientist,

\footnotetext{
${ }^{6}$ I suggest similar arguments support using lottery-selection of political officials, rather than elections. See Guerrero $(2014,2021)$. A similar point is made by Lever (2017).
} 
single-parent, non-native English speaker, disabled person, working-class person, openly gay person, community college student, welfare recipient, woman, AfricanAmerican, Hispanic-American, Muslim-American, first-generation immigrant, and so on. This is not identity politics. It is simply a point about the knowledge one is likely to have come by based on one's life experiences, the evidence one is likely to have encountered. This won't be relevant in every case, perhaps, but there are at least some reasons to think that this kind of diversity might serve as a counterweight to concerns about lay person competence, helping support the veritistic structural quality of systems that employ citizen juries.

Finally, another reason to think citizen juries will protect against misapplication error is simply that, because they have been randomly chosen, they will be appropriately neutral, unbiased, and impartial - and these are epistemically good qualities to have in fact-finders of this kind. This suggestion has deep roots in the law, with the suggestion that jurors should be seen as "blank slates" with respect to particular cases, and there being an ideal "tabula rasa of the impartial juror" that shapes procedural judgments throughout the trial process. As one court put it:

The entire effort of our criminal (civil too) procedure is to secure ... jurors who do not know and are not in a position to know anything of either [the] character [of the parties] or events [on trial] ... The zeal displayed in this effort to empty the minds of the jurors ... [is a sign] that the jury, ... like the court itself, is an impartial organ of justice. ${ }^{7}$

This aim of securing jurors who do not enter the trial process with views about the individual characters or events in question is relevant to the fairness and perceived fairness of the process, but this relevance comes centrally through epistemic considerations. The reason, or at least a main reason, to want "blank slate" jurors is so that they will enter the trial without prejudgments about the central facts of the case or the culpability of the relevant individuals. This is important because those prejudgments might be based on either no evidence at all, or on bad or misleading evidence. Such evidence might still get into the relatively pristine epistemic environment of the courtroom, but to do so it must pass through the extensive epistemic filters discussed earlier, and we should expect that this will be an improvement in terms of the veritistic structural quality of the system.

Because true, complete random-selection might well occasionally result in individuals being chosen for juries for which this "blank slate" ideal would clearly be violated, there are mechanisms by which jurors are chosen and struck for particular petit juries, which I will discuss in some detail in later sections.

There are many questions we might ask about how well actual juries do at securing the aforementioned epistemic benefits. Some of these might turn on particular issues about the structure of juries and the selection of jurors.

There are questions about how competent jurors are at the central epistemic tasks they are given. Should there be any kind of education or competence requirements or thresholds? Should juries be composed wholly of lay citizens, or should there be "mixed" juries that include both lay citizens and legal professionals such as judges, as in so-called "collaborative court" systems?" There are questions about who actually ends up serving on juries and who avoids jury service. Should jury service be more

\footnotetext{
${ }^{7}$ United States v. Parker, 19 F. Supp. 450, 458 (D.N.J. 1937), affd, 103 F. 2 d 857 (3d Cir. 1939), cert. denied, 307 U.S. 642 (1939).

${ }^{8}$ For discussion, see Dudzinski (2013).
} 
compulsory than it presently is? There are questions about which issues should be put to juries, and which should not be. Should juries be involved in complex tax, copyright, patent, and corporate crime cases? Should juries settle questions that are "mixed" questions involving both fact and law, or application of law to fact? Or should they focus only on specific non-legal factual determinations? How should jury deliberations be structured? Should members of a jury deliberate at all, or perhaps only if those deliberations are structured in a very precise way? ${ }^{9}$ Should there be a foreperson? Should efforts be made to ensure that juries are descriptively representative or ideologically representative?

As suggested above, we might consider some of these questions from a non-epistemic vantage point, in terms of what they would mean for political equality, representation, and so on. Importantly, however, I think that in every case there is also a substantial epistemic concern, and these epistemic concerns transmute into moral ones because of the moral importance of ensuring that the State not act against particular individuals except in those cases in which doing so is appropriate.

\section{Interested experts and the epistemology of juries}

We are now in a position to consider the role that interested experts should play with respect to juries. There are questions about whether they might be permitted to present evidence and testify as experts, but I will leave those to the side.

Instead, I will focus on these questions: if we are concerned with veritistic structural quality, should we allow interested experts to serve on juries? Should we allow them to be struck from the jury pool? Does it matter what kind of interested expert they are? Is there an epistemically significant trade-off between their interestedness and their expertise?

\subsection{Challenging potential jurors}

Currently, in the United States, lawyers can eliminate potential jurors either through challenges for cause or peremptory challenges. A challenge for cause is a challenge that aims to disqualify a potential juror for some stated reason, typically including bias, prejudice, or prior knowledge that would prevent impartial evaluation of the evidence presented in court. These are typically unlimited.

In some jurisdictions, a distinction is drawn between for cause challenges that are principal challenges and challenges to the favor. Examples of a principal challenge include challenges based on the fact of a personal relationship to either party to the suit, an interest in the outcome of the suit, either personal or as a member of a corporation, or the relation of master or servant to either party. These are much closer to the earlier definition of narrow interests. Importantly, these kinds of relationships are held to import absolute bias or favor and require the disqualification of the juror as a matter of law.

A challenge to the favor, on the other hand, is one where there is some more remote connection between the juror and some aspect of the case, but which does not create a conclusive presumption of bias. These are granted at the discretion of the presiding judge. Examples of these kinds of connections include instances like the following:

- A retired police officer and a case in which a person is alleged to have fled from a police officer.

\footnotetext{
${ }^{9}$ For one view suggesting that they perhaps should not engage in unstructured deliberation, see Hedden (2017).
} 
- A person who grew up in a neighborhood and a defendant, not personally known to the prospective juror, who also grew up in that neighborhood.

- A person who worked as a dockworker and a suit involving dockworkers.

- A person who was the victim of domestic abuse in a case in which domestic abuse is alleged.

- A person who is a financial analyst in a case involving alleged violation of SEC rules.

A peremptory challenge is a challenge in which it is requested that a juror be excused with no reason given. Each side of a dispute is given a limited number of this kind of challenge.

In the United States, challenges cannot be made on the grounds of race, sex, or religion, although in practice there is no question that these factors enter in, although not explicitly, in who is included on juries.

\subsection{Against allowing challenges to broadly interested experts}

Obviously, there is a significant tension between having either for cause or peremptory challenges and including interested experts on juries. Indeed, it is probably safe to say that both kinds of challenges exist partly to exclude interested experts - even of the broad kind. Among the first people to be challenged by lawyers would be people like Jane Doe, Langston Smith, Sarah Brady, Doctor Brantley, Bea Jackson, and so on depending on the details of the case.

I think this is mistaken. Again, it might be objectionable from grounds of representation and truly having a jury of one's peers. If no one who has had your life experiences, or anything much like them at all, is allowed to serve as a juror in your case, in what sense is it a jury of your peers? But leaving aside moral worries grounded in ideas of equality and representation, there are still significant epistemic worries.

Let us grant that there is a strong case - epistemic and otherwise - for allowing principal challenges: challenges that are based on an individual having a personal relationship with one of the parties or a narrow interest in the outcome of the case. It is certainly true that in some cases, such individuals would be epistemically very useful, possessing relevant, probative evidence as to whether the triggering conditions were satisfied in the particular case. But it is plausible that overall, when considering the veritistic structural quality of the legal system, a system that excluded such jurors would fare better. The potential for distortion, willful ignorance, wishful thinking, intentional deception and misinformation, mis-weighting and unreasonable rejection of evidence, and other forms of epistemic contamination would be significant - even if not present in every case. ${ }^{10}$

The purported case for allowing for cause challenges to the favor or peremptory challenges rests on similar thinking: that, in addition to those with narrow interests, people with broader interests might also introduce epistemic contamination, or at least the reasonable fear of such contamination. The big worry is that rather than focusing on the details of the case in front of them, interested experts will instead bring all of their background knowledge and, in particular, their standing broad interests in the topic, and this will result in biased results. By "biased results" the defender of challenging interested experts means (although not explicitly stated in these terms) worse

\footnotetext{
${ }^{10}$ There is also the worry about long-term stability and acceptance of judgments that are rendered by a jury that is perceived to be biased in this way, whatever the epistemic merits of its judgments. Thanks to Jennifer Lackey for mentioning this further consideration.
} 
epistemic results, worse veritistic structural quality, than systems that just allow for cause challenges to the favor or a limited number of peremptory challenges.

The objection might continue: Livers and Lovers, in particular, will be overwhelmed by their biases, so that whatever epistemic advantage might have been conferred by their expertise will be cancelled out or outweighed by the epistemic disadvantage stemming from their biased interests. This might not be the main problem with Learners, who (it might be suggested) became experts, developing relevant expert methodology and investigative skills and knowledge and so on, prior to developing any distinctive set of interests or values. Perhaps they are less likely to be biased.

Consider, for example, the possibility of having someone like Jane Doe - who has been sexually assaulted, and now works extensively on addressing sexual assault as a social problem - on a jury for a sexual assault case. The worry here is not that Jane Doe is not an expert about sexual assault - what it is like to experience it, how people respond to it, what the procedure for reporting and adjudicating sexual assault claims is like, and so on. The worry instead is that Jane Doe, because of her experience and values and interests, will misapply her expertise in particular cases, so as to be biased against those accused of sexual assault.

In a sense, this is just the very general worry we might have about bias due to interests. As discussed above, let us leave aside cases in which the interested experts have narrow interests in play. This isn't a case where Jane Doe's close friend or family member is the person who was allegedly assaulted.

What about those with broad interests? Perhaps particularly Livers and Lovers, whose broad interests are deeply intertwined with their expertise? Should we still worry about including them on the grounds that, for example, these interests will lead them to misjudge questions outside of their expertise, such as the question of whether the state has proved beyond a reasonable doubt that a particular defendant satisfies both the mens rea and actus reus components of the crime of sexual assault?

It is hard to answer this question in a general way, for all possible interested experts. It is, after all, an empirical conjecture that people with broad interests will be affected by those interests so as to misjudge or be less epistemically reliable than a person without those interests with respect to certain questions - even if they are experts on nearby topics. Still, it seems several responses are available here which would seem to shift the burden to justify excluding interested experts, suggesting the unjustifiability of allowing for cause challenges to the favor or peremptory challenges.

First, it is worth stressing that once we move from narrow interests to broad interests, there are many questions such that everyone who might be brought in to answer them has some distinctive, related interests, plausibly borne of their own personal experience or lack thereof with respect to issues relating to that question. Everyone has a race, everyone has a sex, everyone has a socioeconomic class, everyone has an employment status, everyone has an immigration status, and so on. We should be careful to avoid the mistake of only noticing certain people's interests or potential biases, because they depart from some background baseline expectations about what the "neutral" perspective would look like. Minow (1992) makes this point nicely in discussing the case of Judge Leon Higginbotham, an African-American judge who was asked to remove himself from a race discrimination case, on the grounds that he could not be impartial because of his race. In declining to do so, he noted that "black lawyers have litigated in the federal courts almost exclusively before white judges, yet they have not urged that white judges should be disqualified on matters of race relations." ${ }^{11}$ We might

\footnotetext{
${ }^{11}$ Pennsylvania v. Local Union 542, Int'l Union of Operating Eng'rs, 388 F. Supp. 155, 177 (E.D. Pa. 1974).
} 
ask, then, why should the appropriate "neutral" baseline background experience in a sexual assault case be that one has not experienced sexual assault or been close to someone who has experienced sexual assault? Depressingly, it is not because this kind of experience is statistically uncommon or unlikely to be present in a descriptively representative 12-person jury. The perspective, knowledge, and interests of those who have no familiarity with the experience of being sexual assaulted is actually its own distinctive, plausibly warped and biased perspective. (Pointing this out can also help to push against a public reaction to jury verdicts that might include someone like Jane Doe as distinctively or problematically biased. Once it is noted that all or most will have some biases and blindspots on certain topics, it should be evident that the objectionably biased process would be to include only those who have one kind of bias.)

Second, and related to this last point, being too far from a topic in terms of personal experience and broad interests can bring its own epistemic dangers. Fuller (1978) offers the example of the danger posed by jurors called to judge a sailor charged with threatening another sailor with bodily harm if those jurors knew nothing of the norms and context of waterfront vernacular speech. In particular, they might make too much of one sailor saying to another that he would "stick a knife in your guts and turn it around three times," treating it as a genuine threat, even if in full context it would be clear that it was not. As Minow puts this kind of concern: "I am troubled by the suggestion that bias may arise when one is too close to but not when one is too far from a problem." ${ }^{2}$ Returning to the example of a sexual assault case, if one has no personal experience with sexual assault, one might be surprised by the fact that those who have been assaulted often continue to engage (apparently normally) with the person who perpetrated the assault, they might continue to show that person affection in various ways, they might not report what happened to the police or even talk to close friends about it, and so on. And even if a "disinterested" expert on sexual assault (if there are such people) were brought in to testify to the commonality of all those responses, a person without the relevant experience still might not believe them, because they do not match their (ignorant, uninformed by personal knowledge) expectations of what people would do in these situations. Having someone like Jane Doe on the jury might be effective at combating this kind of ignorance. Allowing the use of for cause challenges to the favor or peremptory challenges to eliminate all people at all like Jane Doe would seem to be a significant problem from a perspective of veritistic structural quality.

Third, when thinking about the way in which the interests of the interested expert might affect their judgment, testimony, and participation on the jury, it is important to stress that, depending on the details of the interested expert's interests, they might well incline in surprising directions when it comes to things like serving on a jury. After all, if Jane Doe cares about decreasing the incidence of sexual assault and making sure that those responsible for sexual assault are held appropriately accountable, that will not incline her to be more careless or less epistemically reliable as a juror than someone who has never thought about sexual assault and doesn't care very much about it as a social problem one way or another. The goal of a person with distinctive interests in this kind of case will not be to just convict as many people accused of sexual assault as possible, regardless of the underlying facts.

From the armchair, there isn't an obvious reason to think that broadly interested experts will make for problematically biased jurors. Indeed, it is plausible that these broadly interested experts will be useful, epistemically speaking, and that we should be happy from a perspective of veritistic structural quality when some of them land

\footnotetext{
${ }^{12}$ Minow (1992: 1206).
} 
on juries related to their interests. This seems particularly true for Learners as a category, but also for the others.

One concern that might be raised is that we don't want any experts on juries whether they are interested or not - and that instead expert input should only come into the legal process through the formal calling of expert witnesses to offer testimony. ${ }^{13}$ There are clear advantages to having expert input come through expert witness testimony. If the testimony is epistemically important, then we should want a process that ensures that all jurors have access to that testimony (rather than leaving it to chance jury selection), that it is properly understood, and that the expert's credentials have been properly vetted and explained to the jury. And there are worries about having unvetted experts offer testimony informally in the context of jury deliberations. That testimony might not be heard by all, it might be an instance of a person claiming expertise when they aren't actually an expert on the topic on which they are testifying, and the content of their testimony might be misunderstood or misapplied.

It is certainly true that in some cases, it would be epistemically best - indeed, epistemically essential - to have expert testimony introduced by an expert witness, even an interested expert witness, for these kinds of reasons. In cases in which this is an option, it is likely to be epistemically better for both interested and disinterested expertise to enter in this way, rather than through the jury. But it might not always be an option. For example, United States Federal Rule of Evidence 702 states that:

A witness who is qualified as an expert by knowledge, skill, experience, training, or education may testify in the form of an opinion or otherwise if:

(a) the expert's scientific, technical, or other specialized knowledge will help the trier of fact to understand the evidence or to determine a fact in issue;

(b) the testimony is based on sufficient facts or data;

(c) the testimony is the product of reliable principles and methods; and

(d) the expert has reliably applied the principles and methods to the facts of the case.

This rule regarding expert testimony doesn't limit expertise solely to scientific or technical expertise, allowing in "specialized" knowledge of other kinds. But, in practice, experts that are allowed to testify are overwhelmingly those who have scientific or technical expertise, or expertise borne of their professional practice or employment. Indeed, the so-called "Daubert" factors (named after the very influential expert testimony case, Daubert v. Merrell Dow Pharmaceuticals, Inc., 509 U.S. 579 (1993)) have served to narrow the conception of expertise that enters as expert witness testimony in precisely these ways. These factors are not requirements that must be met for a person to testify as an expert, but they are a non-exhaustive "checklist" for whether a person should be admitted as an expert witness. These factors import a definite bias toward scientific or technical expertise. These are the factors referenced in Daubert and many cases since:

(1) whether the expert's technique or theory can be or has been tested - that is, whether the expert's theory can be challenged in some objective sense, or whether it is instead simply a subjective, conclusory approach that cannot reasonably be assessed for reliability; (2) whether the technique or theory has been subject to peer review and publication; (3) the known or potential rate of error of the technique or theory when applied; (4) the existence and maintenance

\footnotetext{
${ }^{13}$ Thanks to Jennifer Lackey for articulating this concern.
} 
of standards and controls; and (5) whether the technique or theory has been generally accepted in the scientific community. ${ }^{14}$

Obviously, this narrow conception of expertise would rule out many of the aforementioned examples of individuals as possible expert witnesses. Joseph Hunter, Jane Doe, Langston Smith, Sarah Brady, and Bea Jackson would all be unlikely to qualify. Colonel Marshall might be a borderline case. Ginny Morgan and Doctor Brantley would be more likely to qualify.

Noting that the United States (and many other legal jurisdictions) embraces a narrow, scientific conception of expertise does not undermine the claim that it would, or might be, epistemically best to allow the interested experts discussed above to testify as expert witnesses, rather than having their input come in through jury service. Indeed, one might see the argument of the paper regarding interested expertise as a call to expand the conception of expertise for the purposes of allowing in a wider range of expert witness testimony.

I am inclined to think that we should expand the conception of expertise that is allowed to come in through expert testimony. But I don't think that all of what interested experts can offer (nor experts of all kinds), epistemically speaking, is what they can offer through explicit, formal expert witness testimony. More generally, I'm not inclined to keep experts off of juries. And this will certainly be much harder to do if we expand the conception of expertise, making it plausible that all of us are experts about some topic or other. When people serve on juries, they bring a whole complicated wealth of experience and expertise with them. It won't always be possible for us to control exactly how discussions proceed and how issues emerge, nor what individuals testify to within the deliberative conversation. There is the possibility for mistake, deception, manipulation, overclaiming, overconfidence, and other epistemic vices to enter into these deliberations, precisely because they are deliberations of human beings. Perhaps we should do more to monitor and prevent these epistemic flaws. There are systems that do away with juries entirely for these kinds of reasons. But I don't think allowing interested experts to serve on juries (while not wearing any special 'expert' hat, but just as randomly chosen people) makes any of these things worse. Both actual interested experts and people just pretending to know what they are talking about are capable of "pulling rank," ${ }^{15}$ epistemically speaking, thinking they know more than they do or are smarter than they are, or that their voice is the one that should be heard on this topic. We know this happens in line with demographic factors relating to race, gender, age, class, education, occupation, and even things like height and attractiveness. As mentioned above, there are steps that might be taken and institutional changes that might be made to ameliorate some of these internal deliberative problems, including using structured discussion, formal rules, explicit turn-taking, unnamed written comments, and expert consultation and verification mechanisms. Again, perhaps we should do more in this regard, but it seems a mistake to focus on filtering out experts in general or interested experts in particular.

\section{Reform}

If the above case is convincing, there is a question of what ought to be done, what reforms would need to be made to the current system to improve its veritistic structural quality. This is of course a large and complicated question, and one that can only be

\footnotetext{
${ }^{14}$ Cited in Kumho Tire Co. v. Carmichael, 119 S.Ct. 1167, 1175 (1999).

${ }^{15}$ Thanks to Jennifer Lackey for suggesting this phrase.
} 
answered fully through empirical testing and trial and error. So, what I say here is necessarily suggestive and speculative. I will focus on one main idea along with a few accompanying reforms. These ideas seem worth considering and discussing and perhaps trying out. Here is what I would suggest, focused on what has been the focus of the paper: juries and jury selection. (These might not be the single most significant changes that could be made, particularly given how few cases make it all the way to a jury trial.)

The main reform I would propose would be to use a purely randomly sampled jury, drawn from the relevant political jurisdiction, excluding only those people who have narrow interests or who could be challenged via a principal challenge. Eliminate the use of for cause challenges that would fall under the "challenge to the favor" heading. Eliminate all peremptory challenges. On grounds of veritistic structural quality, we might consider oversampling from groups with relevant experience and expertise, but I will leave that idea for another day.

This would be a significant reform to the current system in the United States. Peremptory challenges in particular have been heralded by the Supreme Court:

The right to challenge a given number of jurors without showing cause is one of the most important of the rights secured to the accused. He may, if he chooses, peremptorily challenge on his own dislike, without showing any cause; he may exercise that right without reason or for no reason, arbitrarily and capriciously. ${ }^{16}$

But it is hard to see what justifies their use. They push against the democratic ideal of a 'jury of one's peers.' And they seem to simply worsen the veritistic structural quality of the system. They are an easy way for many of the worst potential biases of our society to enter into legal decisionmaking, and they are an ongoing source of skewed, nonrepresentative juries - particularly along lines of race, gender, and class. Justice Thurgood Marshall argued that they should be eliminated on precisely these grounds more than 30 years ago in the landmark case, Batson v. Kentucky. ${ }^{17}$ Justice Marshall didn't win that argument, however, and instead that case ushered in what is now 30 years of detailed and largely ineffectual judicial attempts to police the use of peremptory challenges on racial grounds. Peremptory challenges have been called "the last best tool of Jim Crow." 18 Many have called for their abolition. Study after study shows the way in which they are used to sort and exclude on the basis of race and even political ideology. ${ }^{19}$ There has been much less discussion of for cause challenges that are in the "challenge to the favor" category, largely because parties can make easier use of peremptory challenges. But they allow for similar objectionable sorting and filtering on racial and other grounds. And both kinds of challenges make it easy for lawyers to eliminate the interested experts who might happen to be chosen to serve on a jury, thereby eliminating what I have argued is valuable epistemic input.

Along with this change, it might make sense to make a few other changes. It might be worth considering an increase in the number of jurors to 15, say, rather than the standard (but by no means uniform) 12. This would help ensure a more representative sample and increase the odds that people with relevant and different kinds of expertise will be chosen. Relating to this, it might make sense to decrease the proportion that must vote to convict or to find liability: requiring only 13 of 15 , rather than all 15 .

\footnotetext{
${ }^{16}$ Pointer v. United States, 151 U.S. 396 (1894).

${ }^{17}$ Batson v. Kentucky, 476 U.S. 79 (1986, J. Marshall, concurring).

${ }^{18}$ Hoffman (1997).

${ }^{19}$ See, for example, Revesz (2016), DeCamp and DeCamp (2019).
} 
This would help reduce the chance that just one or two interested and possibly biased jurors could prevent conviction or finding of liability. It would also lessen the pressure social, conversational, and otherwise - to conform one's judgment to that of the group.

Obviously, more discussion and experimentation would be needed before these reforms should be implemented. My expectation is that these reforms, taken together, would substantially improve the veritistic structural quality of the legal system as a whole, and in so doing might even reduce the number of bad plea deals that defendants sign on to, if defendants could hope for a fairer, more representative jury trial. If they end up being epistemically valuable reforms, they would also be morally significant: decreasing the number of cases in which the State acts against individuals although the relevant triggering conditions are not actually satisfied in the particular case. ${ }^{20}$

\section{References}

Anazldúa G. (1987). Borderlands/La Frontera: The New Mestiza. San Francisco, CA: Aunt Lute Books.

Baldwin J. (1993 [1961]). Nobody Knows My Name: More Notes of a Native Son. New York, NY: Vintage International.

Brooks T. (2009). 'A Defence of Jury Nullification.' In The Right to a Fair Trial. London: Routledge.

DeCamp W. and DeCamp E. (2019). 'It's Still About Race: Peremptory Challenge Use on Black Prospective Jurors.' Journal of Research in Crime and Delinquency. doi: 10.1177/0022427819873943.

Dudzinski J. (2013). 'Justification for Juries: A Comparative Perspective on Models of Jury Composition.' University of Illinois Law Review 4, 1615-47.

Fantl J. and McGrath M. (2002). 'Evidence, Pragmatics, and Justification.' Philosophical Review 111, 67-94.

Fantl J. and McGrath M. (2009). Knowledge in an Uncertain World. Oxford: Oxford University Press.

Fantl J. and McGrath M. (2012). 'Pragmatic Encroachment: It's Not Just about Knowledge.' Episteme 9, 27-42.

Fuller L. (1978). 'The Forms and Limits of Adjudication.' Harvard Law Review 92, 391.

Goldman A. (1999). Knowledge in a Social World. Oxford: Oxford University Press.

Guerrero A. (2012). 'Lawyers, Context, and Legitimacy: A New Theory of Legal Ethics.' Georgetown Journal of Legal Ethics 25, 107-64.

Guerrero A. (2014). 'Against Elections: The Lottocratic Alternative.' Philosophy and Public Affairs 42, 135-78.

Guerrero A. (2017). 'Living with Ignorance in a World of Experts.' In R. Peels (ed.), Perspectives on Ignorance from Moral and Social Philosophy, pp. 156-85. London: Routledge.

Guerrero A. (2021). 'The Epistemic Pathologies of Elections and the Epistemic Promise of Lottocracy.' In E. Edenberg and M. Hannon (eds) Political Epistemology, pp. 166-92. New York, NY: Oxford University Press.

Harding S. (1993). 'Rethinking Standpoint Epistemology: 'What is Strong Objectivity?' In L. Alcoff and E. Potter (eds), Feminist Epistemologies, pp. 49-82. New York, NY: Routledge.

Hartsock N. (1987). 'The Feminist Standpoint: Developing the Ground for a Specifically Feminist Historical Materialism.' In S. Harding (ed.), Feminism and Methodology: Social Science Issues, pp. 157-80. Bloomington, IN: Indiana University Press.

Hawthorne J. and Stanley J. (2008). 'Knowledge and Action.' Journal of Philosophy 105, 571-90.

Heath J. (2015). 'The Problem of 'Me' Studies.' In Due Course. http://induecourse.ca/the-problem-of-mestudies/.

Hedden B. (2017). 'Should Juries Deliberate?' Social Epistemology 31, 368-86.

Hill Collins P. (1990). Black Feminist Thought. Boston, MA: Unwin Hyman.

Hoffman M. (1997). 'Peremptory Challenges Should be Abolished: A Trial Judge's Perspective.' University of Chicago Law Review 64, 809-71.

Huemer M. (2018). 'A Defense of Jury Nullification.' In D. Boonin (ed.), The Palgrave Handbook of Philosophy and Public Policy. London: Palgrave Macmillan.

\footnotetext{
${ }^{20}$ Thanks to Robert Beddor, Paul Boghossian, Thomas Grundmann, Jason Kawall, Maria Lasonen-Aarnio, Kirk Ludwig, Engel Pascal, Laurie Paul, Asbjørn Steglich-Petersen, Alex Worsnip, and Sarah Wright for helpful comments and discussion at the 2019 Episteme Conference; and a special thanks to Jennifer Lackey for her detailed and very helpful comments on this paper.
} 
Lackey J. (2007). 'Norms of Assertion.' Noûs 41, 594-626.

Landemore H. (2013). Democratic Reason: Politics, Collective Intelligence, and the Rule of the Many. Princeton, NJ: Princeton University Press.

Lever A. (2017). 'Democracy, Epistemology, and the Problem of All-White Juries.' Journal of Applied Philosophy 34, 541-56.

Medina J. (2013). The Epistemology of Resistance: Gender and Racial Oppression, Epistemic Injustice, and Resistant Imaginations. New York, NY: Oxford University Press.

Mills C. (2007). 'White Ignorance.' In S. Sullivan and N. Tuana (eds), Race and Epistemologies of Ignorance. New York, NY: SUNY Press.

Minow M. (1992). 'Stripped Down Like a Runner or Enriched by Experience: Bias and Impartiality of Judges and Jurors.' William and Mary Law Review 33, 1201-18.

Page S. (2007). The Difference: How the Power of Diversity Creates Better Groups, Firms, Schools, and Societies. Princeton, NJ: Princeton University Press.

Revesz J. (2016). 'Ideological Imbalance and the Peremptory Challenge.' Yale Law Journal 125, 2535-49.

\section{Cases cited}

Batson v. Kentucky, 476 U.S. 79 (1986, J. Marshall, concurring).

Kumho Tire Co. v. Carmichael, 119 S.Ct. 1167, 1175 (1999).

Pennsylvania v. Local Union 542, Int'l Union of Operating Eng'rs, 388 F. Supp. 155, 177 (E.D. Pa. 1974). Pointer v. United States, 151 U.S. 396 (1894).

United States v. Parker, 19 F. Supp. 450, 458 (D.N.J. 1937), affd, 103 F. 2 d 857 (3d Cir. 1939), cert. denied, 307 U.S. 642 (1939).

Alexander Guerrero is Professor of Philosophy at Rutgers University - New Brunswick. He works on moral, legal, and political philosophy, as well as topics in epistemology that intersect with those areas. He is the author of Lottocracy: A New Kind of Democracy, forthcoming with Oxford University Press in 2022.

Cite this article: Guerrero A (2021). The Interested Expert Problem and the Epistemology of Juries. Episteme 18, 428-452. https://doi.org/10.1017/epi.2021.36 